\title{
Association analysis of DACTI genetic variants and gastric cancer risk in a Chinese Han population: a case-control study
}

This article was published in the following Dove Press journal:

OncoTargets and Therapy

29 September 2016

Number of times this article has been viewed

Chi Huang,,$*$ Younan Wang, ${ }^{1, *}$ Hao Fan, ${ }^{1}, *$ Xiang Ma, ',* Ran Tang,' Xiangkun Huan, ' Yi Zhu, ${ }^{2}$ Zekuan Xu,' Hao Xu,' Li Yang'

'Department of General Surgery, The First Affiliated Hospital of Nanjing Medical University, ${ }^{2}$ Institute of Tumor Biology, Jiangsu Province Academy of Clinical Medicine, Nanjing, People's Republic of China

*These authors contributed equally to this work

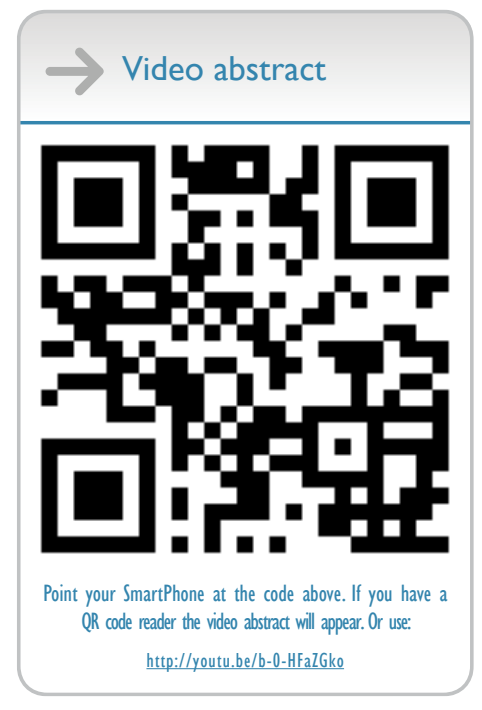

Correspondence: Li Yang

Department of General Surgery, The First Affiliated Hospital of Nanjing Medical University, 300 Guangzhou Road, Nanjing 210029, People's Republic of China $\mathrm{Tel} / \mathrm{fax}+862583718836$ Email pwkyangli@I63.com
Purpose: Disheveled-binding antagonist of beta-catenin 1 (DACT1) is involved in tumorigenesis through influencing cell apoptosis and proliferation. We aimed to investigate the effect of three tag single-nucleotide polymorphisms (SNPs) in DACT1 (rs863091 C > T, rs17832998 C > T, and rs $167481 \mathrm{C}>\mathrm{T}$ ) on the occurrence of gastric cancer (GC), their association with specific clinical characteristics, and consideration of the functional relevance of GC-related SNPs.

Subjects and methods: In this hospital-based case-control study, the genotypes were acquired using the TaqMan-MGB method consisting of 602 cases and 602 controls. DACT1 messenger RNA level was evaluated in 76 paired tumoral and normal tissues using quantitative reverse transcription-polymerase chain reaction. Logistic regression was used to evaluate the associations among the DACT1 SNPs and GC.

Results: We found a significant association between the variant genotypes of rs863091 and decreased risk of GC (TT vs CC: $P=0.009$, adjusted odds ratio $=0.34,95 \%$ confidence interval $=0.15-0.77 ; \mathrm{CT}+\mathrm{TT}$ vs $\mathrm{CC}: P=0.030$, adjusted odds ratio $=0.74,95 \%$ confidence interval $=0.57-0.97)$. In further stratified analyses, rs863091 variant genotypes were associated with a reduced risk of GC in younger individuals ( $<60$ years) and males. No overall significant association with GC risk was observed in SNP rs17832998 or rs167481. Additionally, we assessed DACT1 messenger RNA levels in GC and found that DACT1 expressions of individuals carrying CT and TT genotypes were much higher than those with CC genotype.

Conclusion: Our findings suggest that the DACT1 rs863091 C>T polymorphism may be associated with a decreased risk of GC in the Chinese Han population and influence DACT1 expression.

Keywords: gastric cancer, $D A C T 1$, polymorphism, gene expression

\section{Introduction}

Gastric cancer (GC) is the third leading cause of cancer mortality worldwide, although the incidence in some areas has decreased. ${ }^{1,2}$ Since most patients are diagnosed at advanced stages with limited treatment approaches, GC continues to exhibit a serious health burden. The contributing factors for GC are complicated and not entirely clear. Cumulative evidence has shown that apart from environmental risk factors, genetic factors are also important for the development and progression of GC. ${ }^{3}$ Moreover, our previous studies have revealed the significant association of polymorphisms in $\mathrm{H} 19$, miR-34b/c, JAK2, and RAGE with the susceptibility to gastric carcinogenesis. ${ }^{4-7}$

As a member of DACT family, disheveled-binding antagonist of beta-catenin 1 (DACT1) plays an important role in regulating the planar cell polarity (PCP) pathway. ${ }^{8-10}$ PCP pathway, a significant branch of noncanonical Wnt signaling, is activated through 
the binding of noncanonical Wnt proteins to transmembrane receptors (Frizzled), which results in recruiting cytoplasmic disheveled (Dvl) to the plasma membrane. The PCP pathway affects various cellular processes and plays a significant role in the process of carcinogenesis. ${ }^{11}$ Increasing evidence has shown that DACT1 is associated with several human malignancies, such as GC, ${ }^{12}$ breast cancer, ${ }^{13}$ liver cancer, ${ }^{14}$ lung cancer, ${ }^{15}$ and colorectal cancer. ${ }^{16}$ As to GC, DACT1 is a functional antioncogene that is mainly deactivated by promoter methylation. DACT1 may inhibit nuclear factor

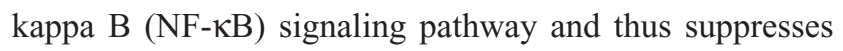
tumorigenesis by promoting cell apoptosis and decreasing cell proliferation. ${ }^{12}$ However, the associations of genetic variants in the DACT1 with risk in malignant diseases have not been reported before, including GC.

In this research, we suggested that single-nucleotide polymorphisms (SNPs) in DACT1 gene were likely to impact the susceptibility to GC. To certify this, we focused on three $D A C T 1$ tag SNPs (rs863091, rs17832998, and rs167481) in a case-control study of 602 patients with GC and 602 healthy controls from the Chinese Han population. Furthermore, we studied the role of the risk-associated polymorphism in regulating its messenger RNA (mRNA) expression in GC tissues and normal tissues, in order to further explore its potential regulation mechanism in adjusting disease risk.

\section{Subjects and methods Subjects}

This hospital-based case-control study consisted of 602 patients diagnosed with GC and 602 noncancer controls. All patients were successively enrolled with newly diagnosed, histopathologically confirmed GC in the First Affiliated Hospital of Nanjing Medical University between 2009 and 2015. The patients without previous history of cancer or previous chemotherapy or radiotherapy participated in our study. As a control group, all age- and sex-matched subjects without self-reported history of malignancies or precancerous condition of GC were randomly recruited from the Department of General Surgery in the same regions during the same period. The control group mainly suffered from varicose veins, aneurysm, hernia, and abdominal trauma. All subjects with no genetic relationship in this study were ethnic Han Chinese from Jiangsu Province or its circumjacent areas. After signing the written informed consent, each patient donated a $5 \mathrm{~mL}$ venous blood sample. Subjects' data including age, sex, diabetes, hypertension, smoking history, and residence were collected by a standard questionnaire.
Subjects were considered as smokers if they previously or currently smoked $\geq 10$ cigarettes per day for at least 2 years. Individuals who had sustained systolic blood pressure $>140 \mathrm{mmHg}$ and diastolic blood pressure $>90 \mathrm{mmHg}$ and/or were presently receiving antihypertensive treatment were considered as hypertensive. Subjects were considered as diabetic if they had a fasting plasma glucose $\geq 7 \mathrm{mmol} / \mathrm{L}$ or random plasma glucose $\geq 11 \mathrm{mmol} / \mathrm{L}$ and with typical symptoms of hyperglycemia (polyuria, polydipsia, and weight loss) or requiring insulin or oral hypoglycemic agents. Rural or urban residence was determined by a questionnaire according to the addresses and data of the subjects collected. The Ethics Committee of the First Affiliated Hospital of Nanjing Medical University approved this study, and written informed consent was obtained from each participant before sample collection.

\section{SNP selection}

We obtained genotype data for Han Chinese within DACT1 released by HapMap public database (HapMap Data Rel 27 Phase II + III, Feb09, on NCBI B36 assembly, dbSNP b126) and used the Haploview program (Broad Institute, Cambridge, MA, USA) to choose the tag SNPs with $r^{2}$ (linkage disequilibrium correlation coefficient) $>0.8$ and minor allele frequency $\geq 0.05$. As a result, three tag SNPs were chosen in the present research: rs863091, rs17832998, and rs167481.

\section{Genotyping}

As described in our previous study, reference techniques were used to extract genomic DNA from peripheral blood leukocytes. ${ }^{17}$ TaqMan-MGB method (Thermo Fisher Scientific, Waltham, MA, USA) was used to acquire all the genotypes of the three SNPs (ie, rs863091, rs17832998, and rs167481). The sequences of the probes and primers used in genotyping are summed up in Table 1 . Utilization of $5 \mu \mathrm{L} 2 \times$ TaqMan Genotyping Master Mix, $0.125 \mu \mathrm{L}$ probes, $0.25 \mu \mathrm{L}$ primers, 10 ng genomic DNA, and $2.5 \mu \mathrm{L}$ double distilled water composed the $10 \mu \mathrm{L}$ reaction mixture. Amplification was performed at $95^{\circ} \mathrm{C}$ for 10 minutes followed by 40 cycles of $95^{\circ} \mathrm{C}$ for 15 seconds and $60^{\circ} \mathrm{C}$ for 1 minute. In accordance with the manufacturer's instructions, the 96-well ABI StepOnePlus Real-Time PCR System (Thermo Fisher Scientific) was used to conduct the amplifications, and allelic discrimination was performed using Stepone v2.2.2 software (Thermo Fisher Scientific). In order to do quality control, each reaction plate contained two positive experimental controls with known genotype and two negative experimental controls (water). ${ }^{4}$ The call rate for each SNP was $100 \%$. 
Table I Information on primers and probes

\begin{tabular}{lll}
\hline SNPs & Primer sequence $\left(\mathbf{5}^{\prime} \mathbf{- 3}^{\prime} \mathbf{)}\right.$ & Probe sequence \\
\hline rs86309I & F-CACCCTGTAAGGACCAACAAACC & C:FAM-TGTGTCAGAGCCCCG-MGB \\
$\mathrm{C}>\mathrm{T}$ & R-GCAGACACGCCTGTTTCGA & T:HEX-TGTGTTAGAGCCCCG-MGB \\
rs 17832998 & F-TGCCTCCGACCTTCAGAGTAAG & C:FAM-CATGCTCGGTGTTCC-MGB \\
$\mathrm{C}>\mathrm{T}$ & R-GGGCTGTACAACTTTGTTCTCCTG & T:HEX-CATGTTCGGTGTTCC-MGB \\
rs $16748 \mathrm{I}$ & F-GCACCTTTCACTGGTGGAAA & C:FAM-ATATTCTGATAGCAG-MGB \\
$\mathrm{C}>\mathrm{T}$ & R-AGACCTACAATATTGGGACAGGA & T:HEX-ATATTTTGATAGCAG-MGB \\
\hline
\end{tabular}

Abbreviations: SNPs, single-nucleotide polymorphisms; FAM, carboxyfluorescein; HEX, hexachloro-fluorescein; MGB, Minor Groove Binder; F, forward; R, reverse.

Additionally, a random number of $\sim 10 \%$ of the samples were subjected to repeated assays by a different person, and the repeatability was $100 \%$.

\section{Real-time polymerase chain reaction analysis of DACTI}

$D A C T 1$ mRNA expression levels were analyzed by quantitative reverse transcription-polymerase chain reaction (PCR) using total RNA extracted from 76 pairs of cancerous and normal gastric tissue samples using Trizol reagent (Thermo Fisher Scientific). Total RNA was reversely transcribed to first-strand complementary DNA using Primescript RT Reagent (Takara, Otsu, Japan). The real-time PCR primers for DACT1 were as follows: forward primer 5'-TGTGAATCCCAAGTACCAGTGT-3' and reverse primer 5'-CCGTCAGACAAAGGAGAAACATT-3'. $\beta$-Actin was used to normalize $D A C T 1$ gene expression levels and amplified with forward primer 5'-AGAAAATCTGGCACCACACC-3' and reverse primer 5'-TAGCACAGCCTGGATAGCAA-3'. Amplification reactions were executed in a $10 \mu \mathrm{L}$ reaction volume containing $0.2 \mu \mathrm{L}$ primers, $5 \mu \mathrm{L}$ Master mix, and $100 \mathrm{ng}$ complementary DNA. The cycling conditions were set at $95^{\circ} \mathrm{C}$ for 5 minutes, followed by 40 cycles at $95^{\circ} \mathrm{C}$ for 10 seconds and $60^{\circ} \mathrm{C}$ for 30 seconds. Real-time PCR was carried out using FastStart Universal SYBR-Green Master (Vazyme, Nanjing, People's Republic of China) with the StepOnePlus Real-Time PCR System in triplicate. The $2^{-\Delta C T}$ algorithm was used for calculating the expression of individual $D A C T 1$ relative to expression of $\beta$-actin. ${ }^{4}$

\section{Statistical analysis}

Differences in genotype frequencies of the three SNPs between cases and controls and demographic characteristics were calculated using Pearson's $\chi^{2}$ tests (for categorical variables) and Student's $t$-test (for continuous variables). The Mann-Whitney rank sum test was used to analyze the quantitative variables departing from the normal distribution. The Hardy-Weinberg equilibrium was assessed for controls using the goodness-of- $\chi^{2}$ test. Associations between the genotypes and alleles and risk of GC were estimated by odds ratios (ORs) and 95\% confidence intervals (CIs). Woolf approximation method was used to compute the crude OR, and the unconditional logistic regression method was used to assess adjusted OR, with adjustments for age, sex, hypertension, diabetes, smoking status, and residence. We used the SPSS Version 22.0 (IBM Corporation, Armonk, NY, USA) to perform statistical analyses. All $P$-values in our study were two-sided, and $P<0.05$ was considered as significant.

\section{Results \\ Characteristics of the study subjects}

A total of $602 \mathrm{GC}$ cases and 602 controls were recruited in this study. The baseline characteristics of GC cases and controls are presented in Table 2. No significant differences between $\mathrm{GC}$ cases and cancer-free controls regarding age and sex $(P=0.087$ and 0.067$)$ were found, which indicated that the frequency matching was adequate. The mean age was 60.6 \pm 10.7 years for cancer patients and 59.5 \pm 12.9 years for controls, respectively. There was no significant difference in distributions of hypertension, diabetes, and residence between cases and controls. The only exception was that smoking was more frequently distributed among patients with GC than controls.

\section{Associations of DACTI tag SNPs and GC risk}

Table 3 presents the association between the genotype of DACT1 SNPs and risk of GC. In the controls, all observed genotype frequencies were in accordance with the HardyWeinberg equilibrium $(P=0.055$ for rs863091, $P=0.404$ for rs17832998, and $P=0.659$ for rs167481). To our data, we found that SNP rs863091 was associated with GC risk. In SNP rs863091, the $T$ allele frequency was obviously lower in the case group (12.2\%; T vs C: $P=0.007$, adjusted $\mathrm{OR}=0.72,95 \% \mathrm{CI}=0.58-0.91)$ than the control group (16.1\%). Compared with the CC genotype, the genotypes 
Table 2 Demographic information

\begin{tabular}{|c|c|c|c|}
\hline Characteristics & $\begin{array}{l}\text { Cases } \\
(\mathrm{N}=602)\end{array}$ & $\begin{array}{l}\text { Controls } \\
(\mathrm{N}=602)\end{array}$ & $P$-value \\
\hline Age (years) ${ }^{\mathrm{a}}$ & $60.6 \pm 10.7$ & $59.5 \pm 12.9$ & 0.087 \\
\hline Sex, n (\%) & & & 0.067 \\
\hline Female & $164(27.2)$ & $193(32.1)$ & \\
\hline Male & $438(72.8)$ & $409(67.9)$ & \\
\hline Hypertension, n (\%) & & & 0.569 \\
\hline No & $430(71.4)$ & $421(69.9)$ & \\
\hline Yes & $172(28.6)$ & $181(30.1)$ & \\
\hline Diabetes, n (\%) & & & 0.174 \\
\hline No & $54 \mid(89.9)$ & $526(87.4)$ & \\
\hline Yes & $61(10.1)$ & $76(12.6)$ & \\
\hline Smoking, n (\%) & & & 0.012 \\
\hline Never & $474(78.7)$ & $508(84.4)$ & \\
\hline Ever & $128(2 \mid .3)$ & $94(15.6)$ & \\
\hline Residence, n (\%) & & & 0.116 \\
\hline Rural & $358(52.6)$ & $331(48.0)$ & \\
\hline Urban & $244(47.4)$ & $271(52.0)$ & \\
\hline \multicolumn{4}{|c|}{ Tumor differentiation, n (\%) } \\
\hline Well & $34(5.6)$ & & \\
\hline Moderate & $122(20.3)$ & & \\
\hline Poor & $446(74.1)$ & & \\
\hline \multicolumn{4}{|c|}{ Depth of tumor infiltration, $\mathrm{n}(\%)$} \\
\hline TI & $90(14.9)$ & & \\
\hline $\mathrm{T} 2$ & $68(11.3)$ & & \\
\hline T3 & $270(44.9)$ & & \\
\hline $\mathrm{T} 4$ & $174(28.9)$ & & \\
\hline \multicolumn{4}{|c|}{ Lymph node metastasis, n (\%) } \\
\hline Negative & $196(32.6)$ & & \\
\hline Positive & $406(67.4)$ & & \\
\hline \multicolumn{4}{|l|}{ Localization, n (\%) } \\
\hline Cardia & $265(44.0)$ & & \\
\hline Noncardia & $337(56.0)$ & & \\
\hline
\end{tabular}

Notes: The bold value indicates statistically significant data. ${ }^{2}$ Mean \pm SD.

TT and $(\mathrm{CT}+\mathrm{TT})$ were associated with a significantly decreased risk of GC (TT vs CC: $P=0.009$, adjusted $\mathrm{OR}=0.34,95 \% \mathrm{CI}=0.15-0.77$; CT + TT vs CC: $P=0.030$, adjusted $\mathrm{OR}=0.74,95 \% \mathrm{CI}=0.57-0.97$ ) after adjustment for age, sex, smoking status, residence, hypertension, and diabetes. However, no significant association with GC risk was observed in SNP rs17832998 or rs167481.

\section{The genotype-phenotype correlation between rs86309I and DACTI expression}

In order to investigate the genotype-phenotype correlation between rs863091 and DACT1 expression, we further analyzed the DACT1 mRNA expression levels in 76 pairs of $\mathrm{GC}$ and normal tissue samples with different genotypes. As illustrated in Figure 1A, compared with the CC genotypes $(0.10 \pm 0.12$ [ $\mathrm{n}=47])$, the relative $D A C T 1$ mRNA expression levels in samples with CT $(0.21 \pm 0.18[\mathrm{n}=25]), \mathrm{TT}(0.28 \pm 0.16$ $[\mathrm{n}=4])$, and CT + TT $(0.22 \pm 0.17[\mathrm{n}=29])$ genotypes were significantly higher $(P<0.05, P<0.01$, and $P<0.05$, respectively) in GC tissue specimens. However, as to the relative DACT1 mRNA expression levels in normal tissue samples, no significant differences between $\mathrm{CC}(0.10 \pm 0.12$ [ $\mathrm{n}=47])$ and CT $(0.08 \pm 0.07[n=25])$, TT $(0.10 \pm 0.07[n=4])$, or $\mathrm{CT}+\mathrm{TT}(0.09 \pm 0.07[\mathrm{n}=29])$ genotypes of the rs 863091 were found (Figure 1B). We did not investigate the allele-specific effect of rs 17832998 and rs 167481 on DACT1, because their associations with GC risk were not observed.

\section{Stratified analysis of polymorphism and GC risk}

We conducted stratified analyses for DACT1 rs863091, rs17832998, and rs167481 polymorphisms based on age, sex, smoking, and residence status, which may have potential influence on genetic effect (Tables 4-6). As to rs863091, a reduced risk of GC associated with the variant genotypes was observed in younger subjects (age $<60$ years) $(P=0.006$, adjusted $\mathrm{OR}=0.58,95 \% \mathrm{CI}=0.39-0.85$ ) but not in older subjects $(P=0.725$, adjusted $\mathrm{OR}=0.94,95 \% \mathrm{CI}=0.66-1.34)$. In male subjects, the rare genotypes were associated with a decreased risk of GC ( $P=0.025$, adjusted OR $=0.70,95 \%$ $\mathrm{CI}=0.51-0.96)$, whereas the association was not statistically significant in female subjects $(P=0.482$, adjusted $\mathrm{OR}=0.84$, $95 \% \mathrm{CI}=0.50-1.38)$. We did not find significant association of polymorphism with the GC susceptibility in terms of smoking status and residence. No significant association with GC risks in any stratified analysis was evident in DACT1 rs17832998 or rs167481.

We also conducted stratified analyses according to tumor differentiation, depth of tumor infiltration, lymph node metastasis, and localization and found no obvious correlations between the variant genotypes and the clinical features of GC (Tables 7-9).

\section{Discussion}

This case-control study is the first to evaluate the association between three tag SNPs in DACT1 genes and the risk of $\mathrm{GC}$ in a Chinese Han population. In our findings, the $D A C T 1$ rs863091 SNP was related to a decreased risk of $\mathrm{GC}$, especially in younger subjects (age $<60$ years) and male subjects. The results indicate that the T allele of DACT1 rs863091 may be a protective factor against GC. In the stratified analysis, we identified more prominent protective effect of rs863091 GC variant genotypes in younger subjects (age $<60$ years) and males. The difference in age may be 
Table 3 Association between DACTI gene polymorphisms and risk of gastric cancer

\begin{tabular}{|c|c|c|c|c|c|c|}
\hline Genotypes & Cases, n (\%) & Controls, n (\%) & Crude OR $(95 \% \mathrm{Cl})$ & $P$-value & Adjusted OR (95\% Cl) & $P$-value \\
\hline Overall & 602 & 602 & & & & \\
\hline \multicolumn{7}{|l|}{ rs86309I } \\
\hline $\mathrm{CC}$ & 463 (76.9) & $430(71.4)$ & 1 & & 1 & \\
\hline $\mathrm{CT}$ & $|3|(2 \mid .8)$ & $150(24.9)$ & $0.81(0.62-1.06)$ & 0.127 & $0.80(0.61-1.05)$ & 0.101 \\
\hline TT & $8(1.3)$ & $22(3.7)$ & $0.34(0.15-0.77)$ & 0.009 & $0.34(0.15-0.78)$ & 0.011 \\
\hline $\mathrm{CT}+\mathrm{TT}$ & $139(23.1)$ & I72 (28.6) & $0.75(0.58-0.97)$ & 0.030 & $0.74(0.57-0.97)$ & 0.026 \\
\hline \multicolumn{7}{|l|}{ Allelic } \\
\hline C & $\mathrm{I}, 057(87.8)$ & $\mathrm{I}, 010(83.9)$ & $0.72(0.58-0.91)$ & 0.007 & & \\
\hline $\mathrm{T}$ & $147(12.2)$ & $194(16.1)$ & & & & \\
\hline HWE & & 0.055 & & & & \\
\hline \multicolumn{7}{|l|}{ rsI7832998 } \\
\hline $\mathrm{CC}$ & $365(62.6)$ & $377(62.6)$ & 1 & & 1 & \\
\hline $\mathrm{CT}$ & $218(36.2)$ & $203(33.7)$ & I.II (0.87-I.4I) & 0.396 & I.II (0.88-I.42) & $0.38 \mathrm{I}$ \\
\hline TT & $19(3.2)$ & $22(3.7)$ & $0.89(0.48-1.68)$ & 0.722 & $0.88(0.47-1.67)$ & 0.701 \\
\hline $\mathrm{CT}+\mathrm{TT}$ & $237(39.4)$ & $225(37.4)$ & $1.09(0.86-1.37)$ & 0.477 & $1.09(0.86-1.38)$ & 0.458 \\
\hline \multicolumn{7}{|l|}{ Allelic } \\
\hline C & 948 (78.7) & $957(79.5)$ & $1.05(0.86-1.27)$ & 0.688 & & \\
\hline $\mathrm{T}$ & $256(21.3)$ & 247 (20.5) & & & & \\
\hline HWE & & 0.404 & & & & \\
\hline \multicolumn{7}{|l|}{ rsl6748I } \\
\hline CC & 16I (26.7) & $176(29.2)$ & 1 & & 1 & \\
\hline $\mathrm{CT}$ & $301(50.0)$ & 294 (48.9) & I.I2 (0.86-1.46) & 0.409 & I.II (0.85-I.45) & 0.464 \\
\hline $\mathrm{TT}$ & $140(23.3)$ & 132 (21.9) & $1.16(0.84-1.60)$ & 0.365 & $1.13(0.82-1.57)$ & 0.447 \\
\hline $\mathrm{CT}+\mathrm{TT}$ & 44I (73.3) & $426(70.8)$ & I.I3 (0.88-1.46) & 0.336 & I. $12(0.87-1.45)$ & 0.371 \\
\hline \multicolumn{7}{|l|}{ Allelic } \\
\hline C & $623(51.7)$ & $646(53.7)$ & $1.08(0.92-1.27)$ & 0.369 & & \\
\hline $\mathrm{T}$ & $58 \mid(48.3)$ & $558(46.3)$ & & & & \\
\hline HWE & & 0.659 & & & & \\
\hline
\end{tabular}

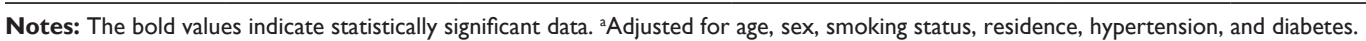

Abbreviations: $\mathrm{Cl}$, confidence interval; DACTI, disheveled-binding antagonist of beta-catenin I; HWE, Hardy-Weinberg equilibrium; OR, odds ratio.
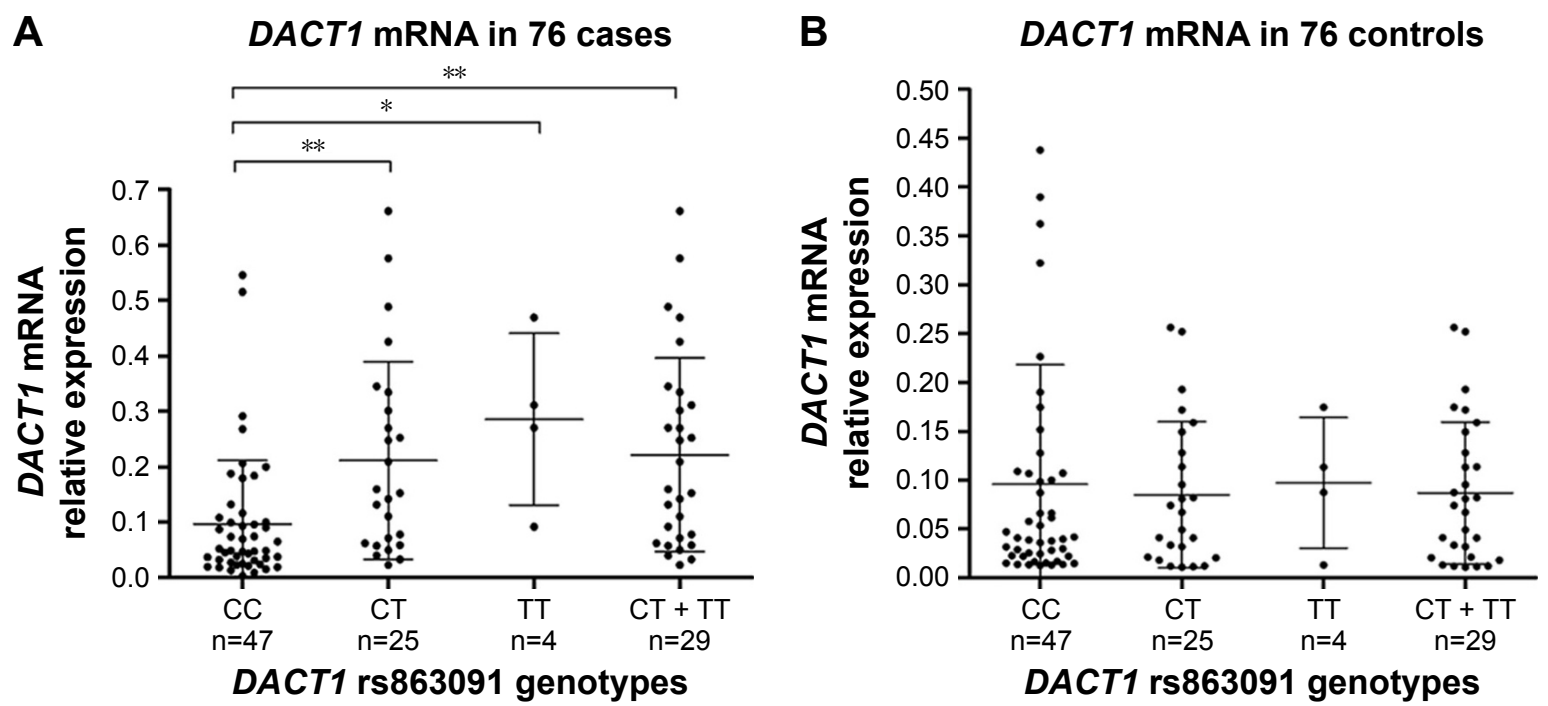

Figure I Correlation between rs86309I genotypes and expression of DACTI mRNA.

Notes: (A) Genotype-phenotype correlation for rs86309I and relative expression levels of DACTI mRNA in $76 \mathrm{GC}$ tissues. Relative DACTI mRNA expression levels were significantly higher for the CT $(0.21 \pm 0.18)$, TT $(0.28 \pm 0.16)$, and $C T+T T$ genotypes $(0.22 \pm 0.17)$ than the CC genotype $(0.10 \pm 0.12)$; $* P<0.05$ and $* * P<0.01$. (B) Genotypephenotype correlation for rs 86309 I and relative expression levels of DACTI mRNA in 76 normal gastric tissues. Relative DACTI mRNA expression levels were similar among the three groups with rs86309/ CC, CT, and TT genotypes.

Abbreviations: DACTI, disheveled-binding antagonist of beta-catenin I; GC, gastric cancer; mRNA, messenger RNA. 
Table 4 Stratified analyses for DACTI rs86309I genotypes in cases and controls

\begin{tabular}{|c|c|c|c|c|}
\hline \multirow[t]{2}{*}{ Variables } & \multicolumn{2}{|c|}{ CT + TT vs CC for rs86309 I } & \multicolumn{2}{|c|}{ Allelic ORs and $95 \%$ Cls for rs86309 I } \\
\hline & Cases, n (\%) & Controls, n (\%) & Adjusted OR $(95 \% \mathrm{Cl})^{\mathrm{a}}$ & $P$-value \\
\hline \multicolumn{5}{|c|}{ Age (years), mean } \\
\hline$\geq 60$ & $85(14.1) / 256(42.5)$ & $80(13.3) / 229(38.0)$ & $0.94(0.66-1.34)$ & 0.725 \\
\hline$<60$ & $54(9.0) / 207(34.4)$ & $92(15.3) / 201$ (33.4) & $0.58(0.39-0.85)$ & 0.006 \\
\hline \multicolumn{5}{|l|}{ Sex } \\
\hline Females & $36(6.0) / / 28(21.3)$ & $48(8.0) / 145(24.1)$ & $0.84(0.50-1.38)$ & 0.482 \\
\hline Males & $103(17.1) / 335(55.6)$ & $124(20.6) / 285(47.3)$ & $0.70(0.5 I-0.96)$ & 0.025 \\
\hline \multicolumn{5}{|l|}{ Smoking status } \\
\hline Smokers & $26(4.3) / 102(16.9)$ & $29(4.8) / 65(10.8)$ & $0.60(0.32-1.14)$ & 0.119 \\
\hline Nonsmokers & $113(18.8) / 361(60.0)$ & $143(23.8) / 365(60.6)$ & $0.79(0.59-1.05)$ & 0.100 \\
\hline \multicolumn{5}{|l|}{ Residence } \\
\hline Rural & $90(15.0) / 268(44.5)$ & $99(16.4) / 232(38.5)$ & $0.78(0.56-1.10)$ & 0.157 \\
\hline Urban & $49(8.1) / 195(32.4)$ & $73(12.1) / 198(32.9)$ & $0.69(0.46-1.04)$ & 0.079 \\
\hline
\end{tabular}

Notes: The bold values indicate statistically significant data. adjusted for age, sex, smoking status, residence, hypertension, and diabetes. CT+TT vs CC was expressed as $\mathrm{CT}+\mathrm{TT} / \mathrm{CC}$.

Abbreviations: $\mathrm{Cl}$, confidence interval; DACTI, disheveled-binding antagonist of beta-catenin I; OR, odds ratio.

Table 5 Stratified analyses for DACTI rs 7832998 genotypes in cases and controls

\begin{tabular}{|c|c|c|c|c|}
\hline \multirow[t]{2}{*}{ Variables } & \multicolumn{2}{|c|}{ CT + TT vs CC for rs I7832998 } & \multicolumn{2}{|c|}{ Allelic ORs and $95 \%$ Cls for rs I 7832998} \\
\hline & Cases, n (\%) & Controls, n (\%) & Adjusted OR $(95 \% \mathrm{Cl})^{\mathrm{a}}$ & $P$-value \\
\hline \multicolumn{5}{|c|}{ Age (years), mean } \\
\hline$\geq 60$ & I $34(22.3) / 207(34.4)$ & I $23(20.4) / / 86(30.9)$ & $0.98(0.7 \mathrm{I}-1.36)$ & 0.924 \\
\hline$<60$ & $103(17.1) / 158(26.2)$ & $102(17.0) / 191(31.7)$ & $1.23(0.87-1.75)$ & 0.237 \\
\hline \multicolumn{5}{|l|}{ Sex } \\
\hline Females & $53(8.8) / I I I(18.4)$ & $75(12.5) / 118(19.6)$ & $0.74(0.47-1.15)$ & 0.173 \\
\hline Males & $184(30.6) / 254(42.2)$ & $150(24.9) / 259(43.0)$ & $1.26(0.95-1.68)$ & 0.105 \\
\hline \multicolumn{5}{|l|}{ Smoking status } \\
\hline Smokers & $45(7.5) / 83(13.8)$ & $33(5.5) / 61(10.1)$ & $0.95(0.53-1.70)$ & $0.86 \mathrm{I}$ \\
\hline Nonsmokers & $192(31.9) / 282(46.8)$ & $192(31.9) / 316(52.5)$ & $1.10(0.85-1.43)$ & 0.468 \\
\hline \multicolumn{5}{|l|}{ Residence } \\
\hline Rural & $139(23.1) / 219(36.4)$ & $114(18.9) / 217(36.1)$ & $1.21(0.89-1.66)$ & 0.227 \\
\hline Urban & $98(16.3) / 146(24.2)$ & III (18.4)/I60 (26.6) & $0.95(0.66-1.35)$ & 0.758 \\
\hline
\end{tabular}

Notes: aAdjusted for age, sex, smoking status, residence, hypertension, and diabetes. CT+TT vs CC was expressed as CT+TT/CC.

Abbreviations: $\mathrm{Cl}$, confidence interval; DACTI, disheveled-binding antagonist of beta-catenin I; OR, odds ratio.

Table 6 Stratified analyses for DACTI rsI6748I genotypes in cases and controls

\begin{tabular}{|c|c|c|c|c|}
\hline \multirow[t]{2}{*}{ Variables } & \multicolumn{2}{|c|}{ CT + TT vs CC for rs I6748I } & \multicolumn{2}{|c|}{ Allelic ORs and $95 \%$ Cls for rs 16748 I } \\
\hline & Cases, n (\%) & Controls, n (\%) & Adjusted OR $(95 \% \mathrm{CI})^{\mathrm{a}}$ & $P$-value \\
\hline \multicolumn{5}{|c|}{ Age (years), mean } \\
\hline$\geq 60$ & $248(41.2) / 93(15.4)$ & $214(35.5) / 95(15.8)$ & $1.14(0.80-1.61)$ & 0.465 \\
\hline$<60$ & $193(32.1) / 68(11.3)$ & $212(35.2) / 81(13.5)$ & $1.06(0.73-1.55)$ & 0.757 \\
\hline \multicolumn{5}{|l|}{ Sex } \\
\hline Females & $119(19.8) / 45(7.5)$ & $138(22.9) / 55(9.1)$ & $1.03(0.64-1.64)$ & 0.917 \\
\hline Males & $322(53.4) / 116(19.3)$ & $288(47.9) / 121(20.1)$ & $1.15(0.85-1.56)$ & 0.377 \\
\hline \multicolumn{5}{|l|}{ Smoking status } \\
\hline Smokers & $95(15.8) / 33(5.5)$ & $65(10.8) / 29(4.8)$ & $1.29(0.70-2.36)$ & 0.413 \\
\hline Nonsmokers & $346(57.5) / 128(21.2)$ & $36 \mathrm{I}(60.0) / 147(24.4)$ & $1.09(0.83-1.45)$ & 0.530 \\
\hline \multicolumn{5}{|l|}{ Residence } \\
\hline Rural & $257(42.7) / 101(16.8)$ & $24 I(40.0) / 90(15.0)$ & $0.94(0.67-|.3|)$ & 0.702 \\
\hline Urban & $184(30.5) / 60(10.0)$ & I $85(30.7) / 86(14.3)$ & $1.46(0.99-2.16)$ & 0.059 \\
\hline
\end{tabular}

Notes: ${ }^{a}$ Adjusted for age, sex, smoking status, residence, hypertension, and diabetes. CT+TT vs CC was expressed as CT+TT/CC.

Abbreviations: $\mathrm{Cl}$, confidence interval; DACTI, disheveled-binding antagonist of beta-catenin I; OR, odds ratio. 
Table 7 Associations between DACTI rs86309I genotypes and clinicopathologic characteristics of gastric cancer

\begin{tabular}{|c|c|c|c|c|}
\hline \multirow[t]{2}{*}{ Variables } & \multicolumn{2}{|c|}{$\begin{array}{l}\text { CT + TT, CC for } \\
\text { rs86309l }\end{array}$} & \multicolumn{2}{|c|}{$\begin{array}{l}\text { Allelic ORs and } 95 \% \text { Cls } \\
\text { for rs86309 I }\end{array}$} \\
\hline & $\mathbf{C T}+\mathbf{T T}, \mathbf{n}$ & CC, $n$ & $\begin{array}{l}\text { Adjusted OR } \\
(95 \% \mathrm{Cl})^{\mathrm{a}}\end{array}$ & $P$-value \\
\hline \multicolumn{5}{|c|}{ Tumor differentiation } \\
\hline Well & 7 & 27 & 1 & \\
\hline Moderate & 24 & 98 & $0.91(0.33-2.54)$ & 0.857 \\
\hline Poor & 108 & 338 & $1.21(0.51-2.89)$ & 0.661 \\
\hline \multicolumn{5}{|c|}{ Depth of tumor infiltration } \\
\hline TI & 17 & 73 & I & \\
\hline $\mathrm{T} 2$ & 21 & 47 & $1.85(0.85-4.00)$ & 0.119 \\
\hline T3 & 52 & 218 & $1.05(0.57-1.94)$ & $0.88 I$ \\
\hline $\mathrm{T} 4$ & 49 & 125 & $1.64(0.87-3.10)$ & 0.128 \\
\hline \multicolumn{5}{|c|}{ Lymph node metastasis } \\
\hline Negative & 44 & 152 & 1 & \\
\hline Positive & 95 & 311 & $1.07(0.7 \mid-1.62)$ & 0.738 \\
\hline \multicolumn{5}{|l|}{ Localization } \\
\hline Cardia & 56 & 209 & 1 & \\
\hline Noncardia & 83 & 254 & $1.30(0.88-1.93)$ & 0.188 \\
\hline
\end{tabular}

Note: aAjusted for age, sex, smoking status, residence, hypertension, and diabetes. Abbreviations: $\mathrm{Cl}$, confidence interval; DACTI, disheveled-binding antagonist of beta-catenin I; OR, odds ratio.

related to a weaker immune system in older individuals ${ }^{17}$ and accumulated exposure to environmental carcinogens, but further research is necessary to clarify the mechanism underlying the association between $D A C T 1$ polymorphisms and age. de Martel et $\mathrm{al}^{18}$ has reported that males are more likely to suffer from GC compared with females by a ratio of about 2:1, and male cardia cancer rates were two to three

Table 8 Associations between DACTI rsl7832998 genotypes and clinicopathologic characteristics of gastric cancer

\begin{tabular}{|c|c|c|c|c|}
\hline \multirow[t]{2}{*}{ Variables } & \multicolumn{2}{|c|}{$\begin{array}{l}\mathrm{CT}+\mathrm{TT}, \mathrm{CC} \text { for } \\
\text { rsI7832998 }\end{array}$} & \multicolumn{2}{|c|}{$\begin{array}{l}\text { Allelic ORs and } 95 \% \text { Cls } \\
\text { for rs I } 7832998\end{array}$} \\
\hline & $\mathbf{C T}+\mathbf{T T}, \mathrm{n}$ & CC, $n$ & $\begin{array}{l}\text { Adjusted OR } \\
(95 \% \mathrm{Cl})^{\mathrm{a}}\end{array}$ & $P$-value \\
\hline \multicolumn{5}{|c|}{ Tumor differentiation } \\
\hline Well & 12 & 22 & 1 & \\
\hline Moderate & 39 & 83 & $0.7 \mid(0.29-1.75)$ & 0.458 \\
\hline Poor & 186 & 260 & $1.43(0.68-3.01)$ & $0.34 I$ \\
\hline \multicolumn{5}{|c|}{ Depth of tumor infiltration } \\
\hline $\mathrm{TI}$ & 31 & 59 & 1 & \\
\hline $\mathrm{T} 2$ & 30 & 38 & $1.39(0.70-2.73)$ & 0.347 \\
\hline $\mathrm{T} 3$ & 105 & 165 & $1.28(0.76-2.13)$ & 0.352 \\
\hline T4 & 71 & 103 & $1.36(0.77-2.39)$ & 0.286 \\
\hline \multicolumn{5}{|c|}{ Lymph node metastasis } \\
\hline Negative & 74 & 122 & 1 & \\
\hline Positive & 163 & 243 & $1.12(0.79-1.60)$ & 0.532 \\
\hline \multicolumn{5}{|l|}{ Localization } \\
\hline Cardia & 106 & 159 & 1 & \\
\hline Noncardia & $|3|$ & 206 & $0.97(0.69-1.35)$ & 0.840 \\
\hline
\end{tabular}

Note: adjusted for age, sex, smoking status, residence, hypertension, and diabetes. Abbreviations: $\mathrm{Cl}$, confidence interval; DACTI, disheveled-binding antagonist of beta-catenin I; OR, odds ratio.
Table 9 Associations between DACTI rs/6748I genotypes and clinicopathologic characteristics of gastric cancer

\begin{tabular}{|c|c|c|c|c|}
\hline \multirow[t]{2}{*}{ Variables } & \multicolumn{2}{|c|}{$\begin{array}{l}\mathrm{CT}+\mathrm{TT}, \mathrm{CC} \text { for } \\
\text { rs } 16748 \mid\end{array}$} & \multicolumn{2}{|c|}{$\begin{array}{l}\text { Allelic ORs and } 95 \% \text { Cls } \\
\text { for rs } 16748 \mathrm{I}\end{array}$} \\
\hline & $\mathbf{C T}+\mathbf{T T}, \mathbf{n}$ & $C C, n$ & $\begin{array}{l}\text { Adjusted OR } \\
(95 \% \mathrm{Cl})^{\mathrm{a}}\end{array}$ & $P$-value \\
\hline \multicolumn{5}{|c|}{ Tumor differentiation } \\
\hline Well & 22 & 12 & I & \\
\hline Moderate & 91 & 31 & $2.08(0.86-5.06)$ & 0.105 \\
\hline Poor & 328 & 118 & I.43 (0.68-3.00) & 0.345 \\
\hline \multicolumn{5}{|c|}{ Depth of tumor infiltration } \\
\hline TI & 67 & 23 & 1 & \\
\hline $\mathrm{T} 2$ & 49 & 19 & $\mathrm{I} .00(0.48-2.1 \mathrm{I})$ & 0.994 \\
\hline T3 & 206 & 64 & $1.10(0.63-1.92)$ & 0.742 \\
\hline $\mathrm{T} 4$ & 119 & 55 & $0.79(0.44-I .4 I)$ & 0.426 \\
\hline \multicolumn{5}{|c|}{ Lymph node metastasis } \\
\hline Negative & 139 & 57 & I & \\
\hline Positive & 302 & 104 & I. $18(0.81-1.73)$ & 0.369 \\
\hline \multicolumn{5}{|l|}{ Localization } \\
\hline Cardia & 202 & 63 & I & \\
\hline Noncardia & 239 & 98 & $0.75(0.52-1.09)$ & 0.130 \\
\hline
\end{tabular}

Note: ${ }^{2}$ Adjusted for age, sex, smoking status, residence, hypertension, and diabetes. Abbreviations: $\mathrm{Cl}$, confidence interval; $\mathrm{DACTI}$, disheveled-binding antagonist of beta-catenin I; OR, odds ratio.

times greater than those in women in a Chinese population. We did not find significant association of polymorphism with the GC susceptibility in terms of smoking status. Tobacco smoke is a confirmed independent risk factor for $\mathrm{GC},{ }^{19}$ so the only exception in the characteristics analysis was that smoking was more frequently distributed in GC patients than controls. Whether the association between polymorphisms and GC risk may be masked by the overwhelming effect of accumulated exposure to tobacco carcinogens in smokers needs further research. Our data indicate that $D A C T 1$ polymorphisms may have an important effect on men with GC. However, further studies are needed to confirm these results.

Human DACT1 gene was located within human genome draft sequence NT_025892.9 (nucleotide position 3937896039387891 in the forward orientation). Previous studies demonstrated that $D A C T 1$, a member of DACT family, plays pivotal roles in the regulation of embryogenesis and cancer development. DACT1 has been considered as a regulator of Wnt signaling through its interplay with Dvl, an important mediator of both the noncanonical and the canonical Wnt pathways. DACT1 antagonizes Wnt signaling by inducing disheveled (Dvl) degradation via a lysosome inhibitor-sensitive and proteasome inhibitor-insensitive mechanism. ${ }^{8,16,20}$ $D A C T 1$ also functions as a tumor suppressor through antagonizing the $\mathrm{Wnt} / \mathrm{b}$-catenin signaling pathway in breast cancer, hepatocellular cancer, and non-small-cell lung cancer. ${ }^{13-15}$ 
In addition, as a cytoplasmic protein, DACT1 interacts and posttranslationally regulates central PCP components Dvl2 and Vang12 and regulates PCP downstream of the Rac1/JNK cascade. Loss of Dact1 leads to posterior malformations in mice. $^{9-11,20}$ Wang et al ${ }^{12}$ reported that DACT1 suppresses tumorigenesis in $\mathrm{GC}$ through inhibiting NF- $\mathrm{KB}$ signaling pathway, and its promoter methylation is significantly associated with tumor aggressiveness. Previously, another study has reported that the methylated $\mathrm{CpG}$ site count of $D A C T 1$ promoter may predict the clinical prognosis of GC. ${ }^{21}$ However, there is no report about the association between $D A C T 1$ genetic variation and risk of cancer in the Chinese Han population.

In this study, DACT1 rs863091 was associated with a significantly decreased GC risk in the Chinese Han population. Moreover, mutational genotypes of DACT1 rs863091 tend to be upregulated in GC tissues, suggesting a genotypespecific effect of this exon SNP on $D A C T 1$, thus supporting a protective role for the susceptibility to $\mathrm{GC}$. The $\mathrm{C} / \mathrm{T}$ polymorphism rs863091 is located in exon 4 of DACT1 gene, and the polymorphism is synonymous. Increasing evidence shows that synonymous polymorphisms have a significant impact on the efficiency of protein translation, the translated protein levels, as well as affecting splicing processes, stability of mRNA, microRNA binding, and nucleosome formation. ${ }^{22,23}$ Synonymous mutations can also influence the accuracy or speed of translation mainly because of the sufficient corresponding transfer RNAs. ${ }^{24-30}$ Moreover, changing of translation rate can impact protein function via folding, ${ }^{31}$ as in most cases folding is executed during translation. ${ }^{32}$ The $D A C T 1$ rs863091 mutation may lead to alterations in DACT1 structure through changing the translational efficiency, which may regulate the $D A C T 1$ function finally. A preceding study pointed out that the effect of $D A C T 1$ on $\mathrm{GC}$ was associated with promoter methylation of $D A C T 1 .{ }^{12,21}$ Hence, we speculate that alterations in $D A C T 1$ function may affect $D A C T 1$ promoter methylation and may influence the interaction of DACT1 and Dv12. Nevertheless, in normal tissues, DACT1 mRNA expression levels in samples with variant genotypes have no significant differences with wild genotype. The primary explanation for the differential findings between normal and cancer tissues might be the relatively small numbers of samples. The differential observations might also be because $D A C T 1$ is a hinge of the complex network of proteins..$^{9-11,20}$ Furthermore, the expression of DACT1 may alter according to other tumor-related genes or due to differences in downstream targets of the enzyme. ${ }^{12}$ Therefore, we speculate that there are some mechanisms working as triggering information exists in tumor tissues but not in normal tissues. However, these hypotheses should be confirmed by our further studies.

There are several limitations in the study that should be considered. First, because it was a hospital-based casecontrol study, selection bias could not be avoided. Nonetheless, the genotype distribution of the controls in our study met the Hardy-Weinberg conditions. Second, the relatively small sample size may have led to limit statistical power to detect a slight effect and may have underpowered geneenvironment interactions in the stratified analyses. Third, we acquired personal information of subjects such as smoking history by questionnaire. Therefore, the inherent selection bias and information bias were unavoidable, which may have led to insufficient statistical power in stratified analysis of smoking status. Fourth, partial missing clinical information on the subjects, such as data on alcohol consumption, histological types, and The Cancer Genome Atlas classifications, prevented further analysis. Moreover, Helicobacter pylori infection is one of independent risk factors of GC. We did not have enough information on $H$. pylori status because it was unethical to perform $H$. pylori tests for every subject, especially for controls. Finally, the study was conducted in the Chinese Han population. Data should be extrapolated to other ethnic groups cautiously.

\section{Conclusion}

Our study for the first time demonstrates that the CT/TT genotype of $D A C T 1$ rs863091 polymorphism is significantly associated with a decreased risk of GC in the Chinese Han population, especially in younger individuals and males. The $\mathrm{T}$ allele may be a protective factor against GC.

\section{Acknowledgments}

This work was supported by the Natural Science Foundation of Jiangsu Province, the Medical ZhongDianRenCai Project of Jiangsu Province (grant number RC2011059), Six RenCai Gaofeng, 333 Project, and the Priority Academic Program Development of Jiangsu Higher Education Institutions (PAPD) (grant number JX10231801).

\section{Disclosure}

The authors report no conflicts of interest in this work.

\section{References}

1. Torre LA, Bray F, Siegel RL, Ferlay J, Lortet-Tieulent J, Jemal A. Global cancer statistics, 2012. CA Cancer J Clin. 2015;65(2):87-108.

2. Jemal A, Bray F, Center MM, Ferlay J, Ward E, Forman D. Global cancer statistics. CA Cancer J Clin. 2011;61(2):69-90. 
3. Resende C, Ristimaki A, Machado JC. Genetic and epigenetic alteration in gastric carcinogenesis. Helicobacter. 2010;15(suppl 1):34-39.

4. Yang C, Tang R, Ma X, et al. Tag SNPs in long non-coding RNA H19 contribute to susceptibility to gastric cancer in the Chinese Han population. Oncotarget. 2015;6(17):15311-15320.

5. Yang C, Ma X, Liu D, et al. Promoter polymorphisms of miR-34b/c are associated with risk of gastric cancer in a Chinese population. Tumour Biol. 2014;35(12):12545-12554.

6. Yang L, Liu D, Liang S, et al. Janus kinase 2 polymorphisms are associated with risk in patients with gastric cancer in a Chinese population. PLoS One. 2013;8(5):e64628.

7. Gu H, Yang L, Sun Q, et al. Gly82Ser polymorphism of the receptor for advanced glycation end products is associated with an increased risk of gastric cancer in a Chinese population. Clin Cancer Res. 2008;14(11) $3627-3632$.

8. Zhang L, Gao X, Wen J, Ning Y, Chen YG. Dapper 1 antagonizes Wnt signaling by promoting dishevelled degradation. J Biol Chem. 2006; 281(13):8607-8612.

9. Wen J, Chiang YJ, Gao C, et al. Loss of Dact1 disrupts planar cell polarity signaling by altering dishevelled activity and leads to posterior malformation in mice. $J$ Biol Chem. 2010;285(14):11023-11030.

10. Suriben R, Kivimae S, Fisher DA, Moon RT, Cheyette BN. Posterior malformations in Dact1 mutant mice arise through misregulated Vang12 at the primitive streak. Nat Genet. 2009;41(9):977-985.

11. Wang Y. Wnt/Planar cell polarity signaling: a new paradigm for cancer therapy. Mol Cancer Ther. 2009;8(8):2103-2109.

12. Wang S, Kang W, Go MY, et al. Dapper homolog 1 is a novel tumor suppressor in gastric cancer through inhibiting the nuclear factorkappaB signaling pathway. Mol Med. 2012;18:1402-1411.

13. Yin X, Xiang T, Li L, et al. DACT1, an antagonist to Wnt/beta-catenin signaling, suppresses tumor cell growth and is frequently silenced in breast cancer. Breast Cancer Res. 2013;15(2):R23.

14. Yau TO, Chan CY, Chan KL, et al. HDPR1, a novel inhibitor of the $\mathrm{WNT}$ /beta-catenin signaling, is frequently downregulated in hepatocellular carcinoma: involvement of methylation-mediated gene silencing. Oncogene. 2005;24(9):1607-1614.

15. Yang ZQ, Zhao Y, Liu Y, et al. Downregulation of HDPR1 is associated with poor prognosis and affects expression levels of p120-catenin and beta-catenin in nonsmall cell lung cancer. Mol Carcinog. 2010;49(5): 508-519.

16. Yuan $\mathrm{G}$, Wang $\mathrm{C}, \mathrm{Ma} \mathrm{C}$, et al. Oncogenic function of DACT1 in colon cancer through the regulation of beta-catenin. PLoS One. 2012;7(3): e34004.
17. Zhu H, Yang L, Zhou B, Yu R, Tang N, Wang B. Myeloperoxidase G-463A polymorphism and the risk of gastric cancer: a case-control study. Carcinogenesis. 2006;27(12):2491-2496.

18. de Martel C, Forman D, Plummer M. Gastric cancer: epidemiology and risk factors. Gastroenterol Clin North Am. 2013;42(2):219-240.

19. Parkin DM. International variation. Oncogene. 2004;23(38):6329-6340.

20. Katoh M, Katoh M. Identification and characterization of human DAPPER1 and DAPPER2 genes in silico. Int J Oncol. 2003;22(4): 907-913.

21. Deng J, Liang H, Zhang R, et al. Methylated CpG site count of dapper homolog 1 (DACT1) promoter prediction the poor survival of gastric cancer. Am J Cancer Res. 2014;4(5):518-527.

22. Waldman YY, Tuller T, Keinan A, Ruppin E. Selection for translation efficiency on synonymous polymorphisms in recent human evolution. Genome Biol Evol. 2011;3:749-761.

23. Chamary JV, Parmley JL, Hurst LD. Hearing silence: non-neutral evolution at synonymous sites in mammals. Nat Rev Genet. 2006;7(2): 98-108.

24. Bulmer M. The selection-mutation-drift theory of synonymous codon usage. Genetics. 1991;129(3):897-907.

25. Gustafsson C, Govindarajan S, Minshull J. Codon bias and heterologous protein expression. Trends Biotechnol. 2004;22(7):346-353.

26. Kramer EB, Farabaugh PJ. The frequency of translational misreading errors in E. coli is largely determined by tRNA competition. RNA. 2007; 13(1):87-96.

27. Stoletzki N, Eyre-Walker A. Synonymous codon usage in Escherichia coli: selection for translational accuracy. Mol Biol Evol. 2007;24(2): 374-381.

28. Hershberg R, Petrov DA. Selection on codon bias. Annu Rev Genet. 2008:42:287-299.

29. Gingold H, Pilpel Y. Determinants of translation efficiency and accuracy. Mol Syst Biol. 2011;7:481.

30. Plotkin JB, Kudla G. Synonymous but not the same: the causes and consequences of codon bias. Nat Rev Genet. 2011;12(1):32-42.

31. Kimchi-Sarfaty C, Oh JM, Kim IW, et al. A "silent" polymorphism in the MDR1 gene changes substrate specificity. Science. 2007;315(5811): 525-528.

32. Komar AA. A pause for thought along the co-translational folding pathway. Trends Biochem Sci. 2009;34(1):16-24.
OncoTargets and Therapy

\section{Publish your work in this journal}

OncoTargets and Therapy is an international, peer-reviewed, open access journal focusing on the pathological basis of all cancers, potential targets for therapy and treatment protocols employed to improve the management of cancer patients. The journal also focuses on the impact of management programs and new therapeutic agents and protocols on

\section{Dovepress}

patient perspectives such as quality of life, adherence and satisfaction. The manuscript management system is completely online and includes a very quick and fair peer-review system, which is all easy to use. Visit http://www.dovepress.com/testimonials.php to read real quotes from published authors. 